HISTORICAL NOTE

\title{
SOME PERSONAL REFLECTIONS ON THE DEVELOPMENT OF ANAESTHESIA IN SRI LANKA
}

\author{
T W Vanniasingham* \\ Former Consultant Anaesthetist, General Hospital, Colombo \\ Past President, College of Anaesthesiologists of Sri Lanka \\ *Corresponding author: 1/19, Wingate Avenue, Eastwood, NSW 2122, Australia
}

Key Words: chloroform, mask, spinal analgesia

In 1947 when I had just qualified as a doctor I was appointed Assistant Anaesthetist of the General Hospital, Colombo in place of a doctor who had gone on three months leave to the UK. I went straight to the Medical Superintendent and told him that I could not do this appointment as I simply did not know what to do. He sent for the senior anaesthetist Dr Lucas who reassured me and asked me to come to the operating theatre the next day and that he will show me what I have to do. So the following morning I went to the theatre and he described to me how to administer chloroform and ether and I watched him do it for three mornings.

The chloroform and ether were administered using the silk mask. This was a cylindrical mask made of celluloid with one end closed off. The closed end had moderate sized perforations to allow air to be drawn in by the patient's inhalations. A folded piece of lint was pushed through the open end to the bottom of the other end with the perforations. One dram of choloroform was measured using a minim measuring vessel and poured on to the lint in the silk mask. The sides of the mask was wiped so that no chloroform spilt on the mask could trickle down on to the patients face as chloroform causes a chemical burn of the skin. The mask was then held over the nose and the closed mouth about half an inch above the face. Sometimes a catheter delivering oxygen was also introduced under the mask through this half inch gap. Intermittently the anaesthetist used to inhale the mask to see if any of the chloroform was still there. If no chloroform was smelt, a further dram of chloroform and two drams of ether was poured on to the lint and anaesthesia continued. Further doses were added as necessary. The anaesthetists fingers of the right hand were on the facial artery as it crossed the mandible - finger on the pulse! The left hand held the chin up and often an oral airway was inserted. This technique gave very good relaxation. The pulse had to be watched very carefully for irregularities.

On the fourth morning, I was put down to anaesthetise for the senior surgeon who used to administer the spinal analgesic for the first case himself. I called one of the anaesthetists to help me lay out the spinal trolley and he came and told me it was all very simple. Without scrubbing his hands or using sterile gloves, he whisked off the cloth covering the spinal trolley. On the trolley there were two sterile enamel bowls with presumably sterile water. Still without scrubbing or wearing gloves he took the syringe and piston, both sterilised by boiling and fitted them telling me that he was not contaminating the "business ends" of the syringe. Next, he took the lumbar puncture needle with the stillete still in it, both sterilised by boiling. Still with his bare hands he withdrew the stillete, fitted the needle to the syringe and flushed it with water from one of the bowls into which a few drops of hydrochloric acid had been added earlier. This he said was to neutralise any alkalinity which decreased the potency of nupercaine. Having flushed it repeatedly a few times, he then flushed it with the 
sterile water in the other bowl, presumably to remove traces of acidity. He then got an attendant to file open the bulb of light nupercaine and withdrew $12 \mathrm{ml}$ into the syringe, disconnected the needle, fitted the stillete into it and laid both the loaded syringe and the needle on the trolley. $\mathrm{He}$ also filled a small syringe with procaine for the subcutaneous injection over the spine. The trolley was covered again and he told me it was now ready for the surgeon. I, like a fool, being only a trainee, pushed the trolley into the theatre for him. It is by god's grace that no spinal meningitis occurred in such cases.

These four days were the only training I had in 1947 and then I was on my own learning from my own mistakes! At that time most abdominal surgery including gastrectomies, gastrojejunostomies and even splenectomies (malarial spleens were fairly common then) were under spinal analgesia because of simplicity. Very few complications occurred but I remember two such cases which were not done by me. Those were the days the surgeons ruled the operating theatres! They were like demi-gods. The patient was a medical student for a cholecystectomy. The usual pre-medication was one ampoule of omnopon/scopolamine one hour before surgery and half an ampoule half hour before surgery. The patients were well doped. This surgeon also used massive doses of light nupercaine, doses from 12 to $14 \mathrm{ml}$ - these doses were really meant for well built caucasian patients. The anaesthetist usually set up a drip of saline and gave an intramuscular injection of ephedrine to counteract the fall of blood pressure. During the course of the operation the patient was restless and talking. The surgeon ordered another half an ampoule of omnopon/scopolamine to be given. The patient died the same night in the ward. No one realised that the large dose of light nupercaine had paralysed the lower thoracic muscles and the patient was actually hypoxic and hence agitated and restless. Further doses of omnopon/scopolamine made the condition worse.

The second complication I remember was a young muscular patient who was given a heavy nupercaine spinal analgesia for dilatation of the urethra. He was dead on the third day after the operation probably from spinal meningitis.
Patients for head and neck surgery were intubated blindly after a general anaesthetic by the older anaesthetists while the younger anaesthetists used thiopentone given rapidly intravenously followed by intubation using Magill's straight bladed laryngoscope. One had to be quick as intubation had to be achieved before the patient lightened from the thiopentone.

From my private conversations with the late $\mathrm{Dr}$ Lucas, the Senior Anaesthetist, I leant that he was the first qualified anaesthetist appointed to the General Hospital, Colombo. I believe he had passed the first ever Diploma in Anaesthetics examination held in London in 1935. Dr Lucas had succeeded Dr Joseph Silva who was considered an expert at the use of chloroform and ether with the Silk mask. I had in fact seen Dr Joseph Silva using rectal ether for a thyroidectomy. I was a third year medical student and was in the operating theater. The anaesthetic was a very satisfactory one.

Dr Lucas was subsequently joined by Dr L M de Silva, Dr Bill Anthonisz and Dr Samahim. I do not know very much about this period except that they were using stovaine, as heavy subarachnoid spinal anaesthetic. This was in the early 1940's when the Second World War was on.

During the Second World War, British and Indian soldiers used some of the wards of the General Hospital and also the operating theaters. The army medical officer anaesthetists used nitrous oxide and ether on an early Boyle's type of machine. They had been amazed to see our anaesthetists using chloroform and ether with such confidence and ease and had tried using it on their cases. Dr Lucas told me that a couple of their patients died one after another. I think they made the mistake of approximating the mask tightly to the face so that in addition to cutting off additional air and oxygen, there was also carbon dioxide accumulation which probably led to ventricular fibrillation. I think the army doctors also introduced thiopentone anaesthesia. Some of our bold surgeons used it for short procedures even in the wards with the help of their house officers!

In my short period of three months as acting anaesthetist from May to July 1947 I used the 
Shipway apparatus and even the Junker's chloroform bottle. The Flagg bottle was also used for endotracheal anaesthesia. There were three holes on the lid of the bottle which was tied to the Oxygen cylinder stand. The first was for the catheter carrying Oxygen to the bottle. The second for a tube to let out the expired air. This was a short tube with a small piece of gauze at the end, which flapped with each expiration. The third hole was connected by a fairly long tube to the endotracheal tube. This of course increased the patient's dead space. The Flagg bottle enabled a fairly good and smooth anaesthetic to be delivered. The bottle was filled upto about one third with ether and the oxygen catheter was above the level of the ether.

I left anaesthetics after three months and after a variety of other jobs was appointed District Medical Assistant, Kuliyapitiya in June 1949. Here I was able to do a couple of appendicectomies and herniotomies using spinal analgesia which I gave before doing the surgery myself.

In May 1950 I got a telegram asking me to report as Acting Anaesthetist, General Hospital Colombo on the sudden death of Dr Samahim. This was probably because I had previously worked as acting anaesthetist for three months. In the period between 1946 and 1950 more anaesthetists had been appointed. They were Drs J. L. C. (Laddie) Fernando, Claude Umagiliya, S. Ponnambalam, Charlie Gunaratne, Jimmy Richards and B S Perera. Dr Laddie Fernando and Dr Claude Umagiliya were the first among them to be sent to the $\mathrm{U} K$ for training and on their return they were the first to use neuromuscular blocking agents short acting relaxants for intubation and $\mathrm{d}$ tubocurarine and gallamine for longer operations. The Boyle's machine was used and also controlled respiration with carbon dioxide absorption by soda lime with long acting relaxants for major abdominal operations. The older anaesthetists still stuck to using light nupercaine subarachnoid analgesia for such cases. The curved blade Macintosh laryngoscope was introduced. I was appointed Resident Anaesthetist in September 1951 which post I held until I left with my wife for the UK in March 1952 to obtain the two part Diploma in Anaesthetics.
In the UK I attended the Basic Sciences Course at the Royal College of Surgeons (held for the primary F.R.C.S) for three months and in September 1952, I sat the part one of the two part D A examination. Unfortunately I could not sit the second part in May 1953 as I was ill with chicken pox. In November 1953 the two part D A was abolished and I had to sit the Final of the first F. F. A. R. C. S. (Fellowship of the Faculty of Anaesthetists of the Royal College of Surgeons) examination. 16 of about 160 passed the examination and I was one of them, by God's grace. I did some postgraduate work seeing the anaesthetic work in specialized hospitals and returned home in June 1954.

While I was away Drs Jimmy Richards, Ponnambalam, Charlie Gunaratne and B S Perera had returned after the two part D A They were entitled to the F. F. A. R. C. S. by merit. The standards of anaesthesia had improved and trainees were appointed to work with them. On my return to Sri Lanka I was appointed supernumerary Consultant Anaesthetist at the General Hospital and also at the Lady Ridgeway and Lady Havelock Women's Hospitals Colombo. During this period I wrote a "Memorandum on the Teaching and Training to be given to Anaesthetists, House Officers, Medical Students and Apothecaries" and forwarded copies to the Director of Health Services, Vice-Chancellor University of Ceylon and the Dean of the Faculty of Medicine. In it I recommended the setting up of a Department of Anaesthesia in the Faculty of Medicine under a Professor of Anaesthetics or even a Sub department in the Department of Surgery under a Senior Lecturer. Alas, no one was interested or even cared to comment!

Dr L M V Attygalle was I believe the second person from Sri Lanka to obtain the F. F. A. R. C. $\mathrm{S}$. by examination. He returned to Sri Lanka sometime after I did in June 1954. Thereafter, many anaesthetists returned from the UK with the F. F. A. and the standard of anaethesia advanced by leaps and bounds. However, I wish particularly to mention Dr A T W P Jayawardene who put cardio-thoracic anaesthesia on a proper footing contributing much to the success of cardio thoracic surgery. It was during his time that the Intensive Care Unit was properly organized. I also 
wish to mention Dr Kenneth Perera who worked with me in Kandy and also Drs Pathmanathan and Gnanasuntheram who were colleagues with me at the General Hospital, Colombo.

In July 1956 I was appointed Consultant Anaesthetist, General Hospital, Kandy and Lecturer in Anaesthetics, Faculty of Dentistry, Peradeniya which posts I held until January 1964. During this time, I sent out a notice to all specialists and house officers concerned at the General Hospital, Kandy on the "The listing and preparation of patients for operation" from the anaesthetists point of view.

I was transferred to General Hospital, Ragama on 01 January 1964 and to General Hospital, Colombo on 01 August 1964. In September 1968, Dr B S Perera and I represented the Association of Anaesthetists of Sri Lanka at the Fourth World Congress of Anaesthesiologists in London on a Commonwealth Foundation Travel grant. I retired on 2 April 1973 on a concession allowing specialists to retire on the abolition of private practice. After retirement I really enjoyed my work in the private sector though I worked much harder. I visited patients before operation preparing them for operation, sometimes postponing them for specialised medical treatment. I also enjoyed looking after the patients after operations, spotting complications and bringing them to the notice of the surgeons. I well remember especially two cases. One was a cholecystectomy after which the surgeon proceeded to do an appendicectomy. (One eminent surgeon once told me that multiple surgery was bad in principle). The patient did very well for two days. I saw him on the third day after operation, checked his blood pressure, and pulse and ordered the necessary intravenous fluids. As I was about to get into my car having completed my rounds, a nurse came running and wanted me to come and see the patient as his pulse was rapid and he was pale. On going back to see the patient, he showed the classical signs of intra-abdominal hemorrhage. I got the nurse to transfer him to the operation theatre and phoned the surgeon to come immediately. The surgeon returned and was surprised to find the patient on the operation table. When I gave him my findings he got ready for a laparotomy. On opening the gall bladder bed was dry, but I told him to look at the appendicectomy area and there we found blood and the appendicular artery spurting. The other case was one of vaginal hysterectomy done in the morning. In the evening when I went to check the patient, I found a suprapubic haematoma and the patient was showing signs of internal haemorrhage. Fortunately, the gynecologist was in hospital at that time doing his consultations. He came at my urgent summons and asked me 'So you think she is bleeding? Yes, I told him, the suprapubic lump cannot be anything else'. This time he opened through the abdomen and found that the ligatures on one of the uterine arteries had slipped and the artery was spurting. The patient made a good recovery.

It was this kind of clinical work that kept my 15 years in the private sector most interesting. When I retired from government service in 1973 and started private practice, I had about one or two cases per week in the private sector and I wondered whether I had done the right thing in retiring prematurely. After 15 years in the private sector I used to work from $5.30 \mathrm{am}$ till $11.30 \mathrm{pm}$ with breaks for meals only. I could hardly handle the number of cases I was called to anaesthetise!

In 1978 when I was the President of the College of Anaesthesiologists of Sri Lanka I went with the heads of the other medical specialties under the leadership of the Junior Minister of Health on a visit to China, on the invitation of the Government of China for two weeks. We were sent to see the integration of traditional medicine and western medicine and also the use of acupuncture. We were treated right royally and visited Shanghai, Hanchow and Nanking. On our return, I submitted a report on the visit from an anaesthetist's point of view to the then Director of Health Services.

In 1989 my wife and I stopped all medical work and left for Auckland when our daughter got a transfer to Auckland Medical College. Subsequently we moved to Sydney where we now reside and where our daughter is a General Practitioner having qualified from Auckland obtained the Fellowship of the Royal Australian College of General Practitioners. 